\title{
As estatais e as PPPs: o project finance como estratégia de garantia de investimentos em infra-estrutura
}

Wagner Frederico Gomes de Araújo

\section{Introdução}

A crise dos anos 70 tem conduzido, nas últimas décadas, a um processo constante de reforma do Estado, com a redefinição do papel do setor público diante da oferta de bens e serviços de infra-estrutura. A transferência dessas atividades para o setor privado é um ponto central nesse processo. As privatizações visavam, entre outros objetivos, a desonerar o setor público dos gastos com grandes investimentos, diminuir o desequilíbrio fiscal, aumentar a eficiência nos setores de infraestrutura pela introdução da competição e garantir investimentos contínuos.

As privatizações, por outro lado, abriram um canal para a estreita interação entre o setor público e o setor privado, de modo a se estabelecerem parcerias para a garantia de investimentos. As alterações das funções do Estado resultaram em diversas instituições, que atendem ao interesse público. Da mesma forma, as empresas estatais remanescentes foram profissionalizadas e passaram a ser players importantes no mercado. 
Uma forma de parceria que tem sido muito difundida há vários anos em outros países e, mais recentemente, no Brasil é o project finance. Trata-se de uma forma específica de arranjo financeiro para a viabilização de investimentos, geralmente de grande vulto, para o qual uma sociedade específica é criada para gerir investimento em infraestrutura. Sua estrutura financeira envolve, como elementos básicos, a mitigação de riscos pela elevação do número de participantes e securitização de receitas futuras do projeto. Ele é especialmente interessante quando combinado com outra forma de parceria, as parcerias público-privadas (PPPs), em que instituições de direito privado e de direito público se unem para atingir um objetivo comum.

Com essa perspectiva, este trabalho visa analisar a estrutura do project finance $\mathrm{e}$ sua relação com o processo de reforma do Estado brasileiro, de modo a se estabelecer uma estratégia de garantia de investimentos nos setores de infra-estrutura por meio de parcerias entre as empresas estatais, de direito privado, e a administração pública, seguindo os princípios das PPPs. Para tanto, após essa introdução, discute-se a crise do Estado, o processo de privatizações e o papel das estatais, com foco no caso brasileiro. Em seguida, é exposto um breve panorama da parceria público-privada nos setores de infra-estrutura, bem como o papel do Estado e do setor privado. As definições e conceitos básicos sobre o project finance são inseridos no tópico 4, que discute também a estrutura financeira do project finance e o papel de seus participantes. Finalmente, conclui-se evidenciando o papel das estatais no project finance, no contexto das parcerias público-privadas entre as estatais e o governo, como estratégia interessante para a viabilização de investimentos em infra-estrutura, fundamentais no processo de desenvolvimento econômico e social do País.

\section{Crise do Estado, privatizações e o papel das estatais}

A década de 1970 foi marcada por intensa participação do Estado na economia em todo o mundo, especialmente no Brasil. Essa participação se deu, em grande parte, na participação de empresas públicas oferecendo infra-estrutura para o setor privado. O Estado brasileiro, durante 50 anos (1930-1980), criou e absorveu empresas do setor privado devido a vários motivos, como o nacionalismo econômico, o socorro a empresas privadas, os recursos insuficientes por parte do setor privado em setores estratégicos da economia nacional e os riscos elevados em investimentos de infra-estrutura com grandes períodos de maturação ${ }^{1}$.

Martins (1985, p. 43) aponta que a participação do Estado brasileiro na economia, durante a década de 1970, foi caracterizada por um movimento de forças centrípetas - de concentração de recursos no governo federal - e de forças centrífugas - de disseminação de agências e empresas independentes e relativamente autônomas para a alocação dos recursos anteriormente mencionados. Conforme o autor, somente de 1971 a 1976, foram criadas 131 empresas estatais, sendo 67 pela União, 59 por estados e 5 por municípios.

Havia cerca de 300 empresas estatais, somente no âmbito federal, em 1979. Essas empresas variavam desde bancos até siderúrgicas, empresas de petróleo e hotéis, entre outros setores. Segundo Pêgo Filho, Lima e Pereira (1999, p.11), entre 1970 e 1981 a poupança bruta do setor produtivo estatal federal correspondeu a 3,68\% do 
PIB, em média, representando 18,68\% de toda a poupança bruta do setor privado.

Além disso, a década de 1970 caracterizou-se como período de déficit público elevado para o equilíbrio macroeconômico, bem como de existência de níveis de inflação acima do que seria desejado. Ademais, o expansionismo estatal levou a grandes projetos de infra-estrutura sob a responsabilidade do Estado, o que exigiu grandes montantes de capital para sua implementação.

A partir da primeira e, principalmente, da segunda crise do petróleo em 1973 e 1978, respectivamente, houve uma deterioração das contas públicas da maioria dos países, gerando graves desequilíbrios macroeconômicos. Nesse contexto, o Estado brasileiro perdeu praticamente toda sua capacidade de investimento, o que adveio do progressivo endividamento público. No âmbito microeconômico, ocorreu forte contração dos empréstimos e financiamentos externos a empresas nacionais, tanto estatais quanto privadas. As empresas estatais, portanto, não possuíam mais recursos disponíveis para grandes empreendimentos de infra-estrutura. Essa redução de despesas implicou deterioração do estoque de capital em infra-estrutura e, conseqüentemente, gerou estrangulamentos em setores importantes para a retomada do desenvolvimento econômico.

Em vários países, a reação às crises da década de 1970 foi seguida por processos de reforma do Estado, com a diminuição de seu papel como provedor de infraestrutura, gerando uma onda de privatizações e concessões ao setor privado. $\mathrm{Na}$ Grã-Bretanha, o lema tornou-se o rolling back the State ${ }^{2}$ durante o governo Thatcher, quando, além das privatizações, foram disseminados contratos de desempenho para os prestadores de serviços de infra-estrutura ou de utilidade pública (Macedo; Alves, 1997). Na Nova Zelândia, considerado um dos países com reformas mais radicais, foram implementadas grandes mudanças macroeconômicas, com um agressivo programa de privatizações, além da terceirização de várias atividades estatais (CARvalho, 1997).

A estratégia das privatizações surgiu como tentativa de ajuste nas contas públicas, por meio da venda de ativos

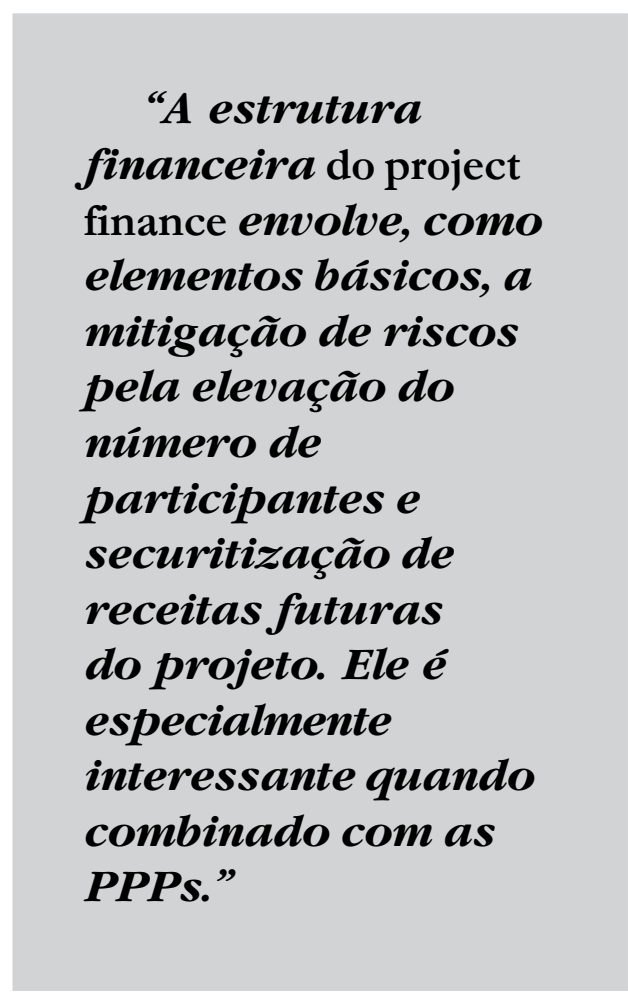

produtivos do Estado, seja para a redução do estoque da dívida pública, seja para a redução da demanda de recursos fiscais para gastos em infra-estrutura. Dessa forma, uma das principais justificativas para a privatização, no âmbito macroeconômico, foi o ajuste fiscal. Mais empresas privadas significavam, outrossim, maior arrecadação tributária para o governo, o que também poderia contribuir para a 
melhora das contas públicas. No plano microeconômico, as privatizações foram justificadas pelos ganhos de eficiência das empresas sob o controle privado e pela sua maior capacidade de investir. Giambiagi e Além (2000, p. 387) apontam que não se pode garantir maior eficiência apenas pela transferência ao setor privado, não havendo diferenças significativas entre ambos, sendo que o principal contraste é que as empresas estatais também têm papel importante na política econômica do governo ${ }^{3}$.

No Brasil, podem-se identificar três fases da privatização (PINHeIro; Giambiagi, 1997):

a) primeira fase: década de 1980 Essa fase se deu por um processo de "reprivatizações", com o objetivo de sanear a carteira do BNDES 4 , o que ocorreu sem a privatização de grandes empresas estatais. Essa fase permitiu ao BNDES adquirir know-bow para se tornar o principal agente de privatizações posteriormente.

b) segunda fase: de 1990 a 1995 - Em 1990, foi lançado o Plano Nacional de Desestatização (PND). Nessa fase, ocorreu a venda de empresas tradicionalmente estatais, além da privatização de setores inteiros. A privatização significava ainda uma peça importante na estratégia do governo de ajuste macroeconômico. Grandes empresas, como a Usiminas, escolhida para inaugurar o processo, foram privatizadas.

c) terceira fase: a partir de 1995 - Em 1995, foi aprovada a Lei de Concessões, estabelecendo regras para a exploração de serviços públicos pelo setor privado, abrindo caminho para um processo de maciça privatização, principalmente nos setores de infra-estrutura e serviços públicos, como telecomunicações e energia elétrica.

Com a privatização dos serviços públicos a partir de 1995, foi necessário um esquema de regulação das empresas privadas que atendiam aos cidadãos, pois, a despeito de serem de iniciativa privada, os serviços públicos têm de ser garantidos pelo Estado. Há ressalvas, contudo. No caso de energia elétrica, por exemplo, a maioria dos consumidores não pode simplesmente trocar de fornecedor caso não esteja satisfeito com a qualidade ou com o preço dos serviços. Via de regra, os interesses das concessionárias não são convergentes com os objetivos do sistema regulatório. Em ambiente institucional em que as agências reguladoras ainda são fracas e com baixa capacidade de enforcement, somando-se a isso a baixa mobilização política da sociedade brasileira, é plausível esperar resultados insatisfatórios no fornecimento de bens e serviços. Tais questionamentos nos levam ainda a discutir a real capacidade de regulação dos ambientes de prestação de serviços públicos, afetando, assim, toda a sociedade. O Estado deve, portanto, buscar assegurar a satisfação dos cidadãos-consumidores por meio de sistemas de regulação sobre empresas prestadoras de serviços públicos. O Estado simplesmente delega ao setor privado sob condições e prazos acordados, tendo o setor privado a obrigação de investimentos previamente definidos (Moreira; Carneiro, 1994, p.31).

Dessa forma, a interação entre o setor público e o setor privado, inclusive as estatais, tem de ser contínua, pois, com base nessa interação, será consolidada a posição do setor privado em infra-estrutura. Adicionando o fato de o Estado brasileiro ainda ocupar papel fundamental na economia nacional e a melhora do cenário macroeconômico na década de 1990, criase condição para que se efetive a parceria público-privada nos setores de infraestrutura. 


\section{A parceria público-privada em infra-estrutura}

A discussão sobre a parceria públicoprivada reside, inicialmente, nos requisitos para sua viabilização. Moreira e Carneiro (1994) apontam duas condições básicas para sua efetivação:

a) o consenso de que novos investimentos em infra-estrutura não podem ser mantidos apenas pelo governo ou apenas pelo setor privado;

b) a definição pelo Estado dos setores de infra-estrutura em que é desejável maior interação com o setor privado.

Ademais, são necessárias outras condições para a efetivação da PPP. A estabilidade econômica é favorável a novos investimentos, pois reduz os riscos e as incertezas. A credibilidade do governo e do país complementa a segurança da estabilidade macroeconômica, possibilitando a capitação de recursos a taxas de juros mais atraentes, pois o risco de default é menor. A existência de ambiente regulatório adequado trata da transparência e financiar investimentos. Um sistema financeiro desenvolvido, do mesmo modo, amplia as possibilidades de financiamento de projetos de infra-estrutura, além de ampliar a possibilidade de hedge (cobertura). Um mercado de seguros maduro possibilita mitigar riscos típicos de incertezas dos projetos de longo prazo e de longa maturação. O desenvolvimento dos fundos de pensão contribui para a alavancagem de projetos de longa maturação, pois os fluxos de despesas dos fundos são realizados em longo prazo. Essas condições refletem o fato do setor privado buscar ambiente estável e previsível, em que as incertezas são minimizadas. Assim, a PPP pode-se concretizar mesmo que uma ou mais dessas condições não esteja presente e desde que o setor privado avalie a operação em um risco aceitável.

Kettl, citado em Pereira e Spink (1998, p. 98), aponta quatro diferentes situações de interação entre o setor público e o privado, sendo cada um caracterizado por uma perspectiva de governo. Essa tipologia é resumida no Quadro 1, a seguir.

\section{Quadro 1: Interação público-privada}

\begin{tabular}{|l|l|}
\hline Setor privado & Perspectivas \\
\hline Beneficiários de serviço público & Reatividade \\
Cidadãos-contribuintes & Eficiência \\
Formuladores de políticas & Responsabilização \\
Parceiros na oferta de serviços & Eficácia \\
\hline
\end{tabular}

Adaptado de: Kettl, citado em Pereira e Spink (1998, p.98).

estabilidade das regras seguidas pelos agentes privados nos mercados de serviços públicos e de infra-estrutura, possibilitando perspectiva de investimentos de longo prazo ao setor privado. O desenvolvimento do mercado de capitais possibilita maior facilidade na captação de recursos para
Primeiramente, o setor privado podese caracterizar como beneficiário de serviços públicos, sem intervenção direta no seu provimento. Sua perspectiva é de reatividade diante da prestação de serviços pelo Estado. Na segunda abordagem, o setor privado considera-se um tax-payer, 
que deseja ver uma redução do Estado para pagar menos tributos, contudo busca o mesmo nível de serviço, focando-se, assim, na eficiência dos gastos públicos. $\mathrm{Na}$ terceira categoria, o setor privado participa diretamente da formulação de políticas públicas, exigindo a responsabilização pelos atos do governo (accountability). Por fim, a última categoria abre espaço para a PPP, pois o setor privado é parceiro na oferta de serviços e cobra do governo a eficácia em suas ações, ou seja, fazer com que elas alcancem suas metas e objetivos.

\section{Modelos de parceria público- privada}

Diversas são as formas e modalidades de PPP. Cada uma apresenta uma estrutura básica com arranjos e padrões bem definidos, que visam a adequar a parceria aos objetivos desejados, além de viabilizar sua implantação. Segundo Moreira e Carneiro (1994, p. 32), podem-se, sucintamente, classificar os modelos de PPP em:

a) BOT (Build-Operate-Transfer): mecanismo clássico de concessão para exploração, construção e prestação de um serviço por período determinado, ao fim do qual o projeto retorna ao Estado. Podese citar, nesse caso, a exploração de serviços de telefonia celular da "Banda B", cujo direito de exploração, e somente este, foi inicialmente vendido pelo Estado;

b) BTO (Build-Transfer-Operate): trata-se de modalidade em que a construção é separada juridicamente da operação. Uma empresa do setor privado constrói o empreendimento e, antes da exploração do serviço, entrega-o ao Estado, que passa a ser o detentor do direito de concessão e, mediante outro dispositivo jurídico, concede a exploração à mesma empresa ou a outra. Pode-se mencionar, como exemplo desse modelo, a construção de uma hidrelétrica;

c) $B O O$ (Build-Own-Operate): mecanismo análogo ao $B O T$, com a diferença de que não há prazo final de concessão, sendo a propriedade do projeto totalmente privada, sem retorno do empreendimento ao Estado. As usinas termelétricas e pequenas hidrelétricas particulares estão incluídas nesse modelo;

d) BBO (Buy-Build-Operate): neste caso, a venda representa a transferência de propriedade de um ativo já em operação, acompanhada da obrigação de operação e de eventual expansão por parte dos novos controladores. Incluem-se nessa modalidade a operação e a expansão dos serviços das empresas de telefonia privatizadas;

e) LDO (Lease-Develop-Operate): o Estado arrenda um ativo existente ao setor privado, exige a realização de melhorias e pequenos investimentos, em geral de recuperação, e firma um contrato de operação privada. Algumas concessões de rodovias adotam esse formato de parceria;

f) CAO (Contract-Add-Operate), Super Turnkey e Operations and Maintenance Contract. consistem em formas de terceirização dos serviços públicos, podendo englobar a realização de pequenos investimentos, não caracterizando uma concessão.

Em geral, os modelos de PPP envolvem um consórcio entre participantes para administrar uma concessão, constituindo uma Sociedade de Propósito Específico (SPE), ou Special Purpose Company (SPC), com personalidade jurídica distinta dos sócios ou controladores. Uma SPC pode envolver diversos participantes, que se incluem, basicamente, em três categorias: os sócios controladores, os sócios minoritários e os patrocinadores. Cada grupo possui diversos interesses no projeto, o que 
reflete suas ações sobre esse projeto. Diante desses interesses, os grupos se articulam para complementar e somar seus recursos para a exploração dos serviços. Uma das principais modalidades para a montagem de consórcio destinado a explorar um serviço que têm sido desenvolvidas atualmente é o Project Finance. Este pode ser um importante instrumento para a participação das estatais em PPPs, tema que será aprofundado no tópico seguinte.

\section{O project finance}

O project finance ou project financing $(\mathrm{PF})$ é, segundo Azeredo (1999), uma modalidade específica de financiamento de projetos, em que uma pessoa jurídica é constituída especificamente com o intuito de realizar o projeto ou oferecer determinado serviço, especialmente em infra-estrutura. Segundo Borges (1998, p. 111),

"Os exemplos mais comuns de operações de project finance que vêm sendo executados no mundo estão na área de infra-estrutura, envolvendo reservatórios de petróleo, refinarias, plataformas, campos petrolíferos, oleodutos convencionais, indústria petroquímica, hidrelétricas, termelétricas (energia em geral), transportes, sistemas de trânsito de massa, plantas de manufatura industrial, mineração, siderurgia e saneamento básico.”

Para Nevitt e Fabozzi (1995), o PF é "o financiamento de uma determinada unidade econômica, no qual o credor se satisfaz em olhar inicialmente para o fluxo de caixa e para as receitas desta entidade como a fonte de pagamento do empréstimo e para os ativos desta unidade econômica como os colaterais para o empréstimo". Conceito análogo é definido por Finnerty (1999), em que a expressão diz respeito à captação de recursos para financiar o investimento de capital economicamente separável, ou seja, de SPEs. Os provedores de recursos vêem o fluxo de caixa e ativos do projeto como fonte primária de recursos para atender ao serviço da dívida (juros), mais a amortização do principal, sendo que os fluxos de recursos são definidos de acordo com as características do fluxo de caixa.

Um traço fundamental na definição e distinção do project finance das demais modalidades de financiamento, em especial do corporate finance ${ }^{5}$, é a concessão de crédito a uma entidade jurídica independente, as SPEs ou SPCs. Dessa forma, a estrutura do financiamento está alicerçada na capacidade financeira do projeto a cargo da SPE, sendo que a decisão dos credores será baseada na perspectiva de o projeto remunerar o capital investido com seu próprio fluxo de caixa, ou seja, sem solidariedade dos acionistas. Como as SPEs são empresas independentes, pode-se aproveitar a modalidade project finance para se obter melhor rating $\mathrm{em}$ seus financiamentos.

Assim, de forma geral, o conceito de PF envolve a implementação de empreendimento, geralmente de grande vulto, por pessoa jurídica ou unidade econômica com fins específicos, em que os financiadores baseiam seus empréstimos na capacidade futura do fluxo de caixa do empreendimento, existindo garantia colateral dos credores (lenders). Os credores, para aceitar o projeto, precisam estar cientes do knowhow na área do projeto dos administradores do empreendimento, da capacidade de os gestores implementarem o projeto e negociarem mecanismos financeiros com a comunidade financeira, bem como das possibilidades de fluxos financeiros estáveis. 
A estruturação do $P F$ exige uma série de instrumentos financeiros, comerciais e jurídicos para mitigação de riscos e controle eficiente sobre os fluxos financeiros do projeto, o que inclui a criação de escrow account (conta-garantia bloqueada) para arcar com exigibilidades e fluxos operacionais. A origem do project finance está exatamente no intuito de os participantes (players) compartilharem e mitigarem riscos, evitando concentrá-los em único empreendimento ou setor.

A alternativa do PF apresenta-se especialmente interessante em três tipos de empreendimentos:

a) investimento de grande porte, desobrigando os empreendedores (sponsors) quanto à concessão de garantias. Os débitos dos financiamentos constam somente no balanço da SPE (off balance, para os empreendedores);

b) envolvimento de empresas que, associadas, apresentam sinergias positivas, podendo haver agregação de potencial de mercado, tecnologia, experiência na execução e montagem do projeto e capacidade operacional. O exemplo mais comum é quando empresas demandantes e concorrentes se unem a fornecedores e construtores, montando uma SPE para a geração própria de energia elétrica;

c) implantação de projetos de infraestrutura em regime de concessão, em que o setor privado não está disposto a assumir aportes elevados de recursos. O envolvimento de número maior de empresas e agências governamentais dá estabilidade às regras de concessão.

Apesar da vasta experiência mundial no $P F$, no Brasil a introdução dessa modalidade de financiamento ocorreu somente na década de 1990, com o Plano Nacional de Desestatização, que iniciou a privatização de grandes empresas dos setores de infra- estrutura e fez o setor privado demandar recursos para novos investimentos.

Existe uma peculiaridade no caso brasileiro, que deve ser ressaltada. Em um projeto de investimento com recursos orçamentários diretos do Estado, não costuma haver financiamento, exceção feita aos empréstimos externos. No caso de empresas estatais, os financiamentos podem ser obtidos de agentes públicos, como o BNDES, do setor privado e do exterior, geralmente com o aval do Tesouro Nacional. Tal fato reduziria o risco de crédito para os bancos e credores, já que a contínua arrecadação tributária diminuiria a possibilidade de falência do negócio. Quando se trata de concessão de serviços públicos, o direito brasileiro impossibilita que os credores possam assumir a conclusão da implantação ou a operação do projeto, cuja prática é considerada fraude ao processo licitatório. Daí a conclusão de que, no direito brasileiro, só é possível implantar o $P F$ com pessoas jurídicas de direito privado, de controle estatal ou privado. Essa característica, contudo, não deve ser considerada como grande obstáculo para a viabilização de PPPs pelo PF, já que o governo pode agir por suas empresas estatais, ainda muito significativas na economia.

Giambiagi e Além (2000, p. 432-433) apontam duas características importantes para a recém-popularização do $P F$ no Brasil. A primeira é a solução para a ausência de garantias, um problema tradicional de projetos de grande porte, sendo a garantia o próprio fluxo de caixa do projeto. A segunda, no caso de empresas estatais, é a possibilidade de realizar investimentos off balance, que seriam desvinculados das estatísticas de déficit público. Uma vantagem explícita do $P F$ é que os players são solidários entre si "no projeto" 
e não guardam nenhuma relação em seus outros negócios. Por isso o PF possui uma estrutura financeira muito peculiar.

Estrutura financeira e participantes do project finance

$\mathrm{Na}$ estrutura financeira do $\mathrm{PF}$, as partes financiadoras do projeto procuram, por meio de operação integrada e conjunta, estabelecer as receitas a serem geradas com a operação do projeto, para a amortização utilização da redução de riscos por meio de sua repartição (unbundling). Essa repartição, como aponta Rodrigues Júnior (1997, p. 12), envolve a utilização de títulos e derivativos. Como dito anteriormente, a estrutura do PF baseia-se na criação de uma SPE, em que ocorre a separação dos riscos do negócio e o risco dos financiadores. Dessa estrutura surgem diversos participantes, tendo a SPE como ponto central. A Figura 1, a seguir, ilustra a estrutura resumida do $P F$.

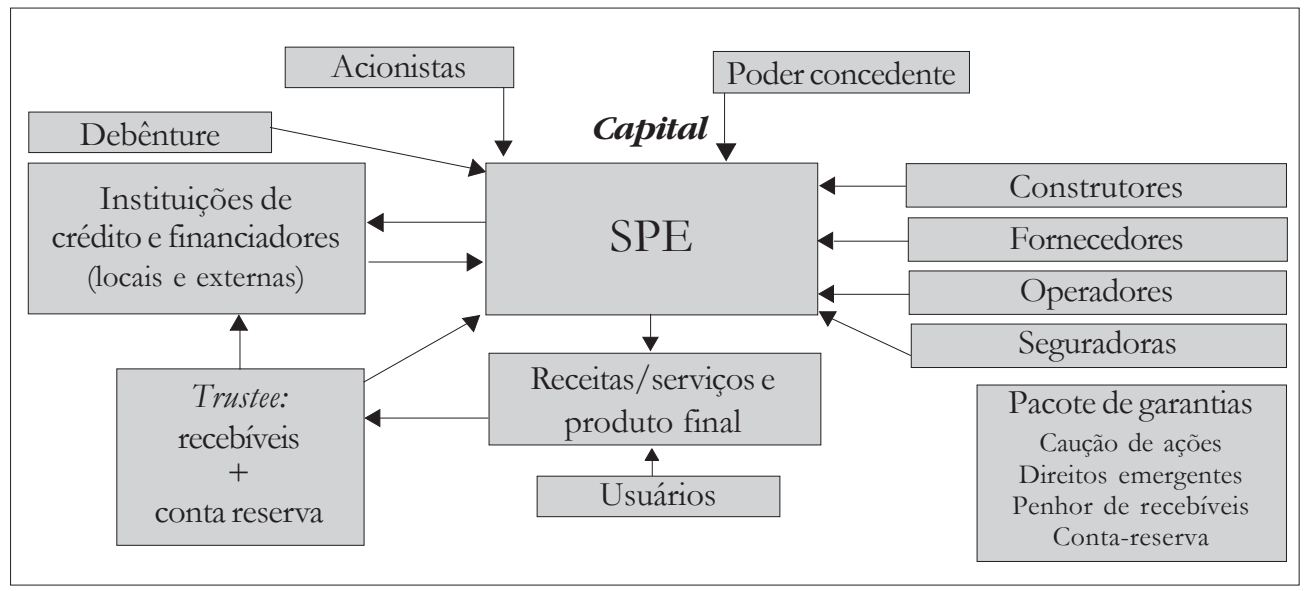

Fonte: Borges e Faria, 2000, p. 251

\section{Figura 1: Estrutura resumida do project finance}

do investimento, ou seja, a securitização das receitas ou dos recebíveis. A securitização envolve a transformação de crédito em título, e os recebíveis são ingressos esperados no fluxo de caixa. A grande vantagem dessa operação está na conversão de ativo futuro em ativo de liquidez imediata, antecipando os recebimentos do fluxo de caixa. Dessa operação pode surgir o fluxo inicial dos projetos, ao mesmo tempo que os credores têm a garantia do recebimento do fluxo de caixa futuro. Esse é um ponto central da estrutura do PF. Outra característica a salientar é a intensiva
Nessa estrutura, podem-se identificar os seguintes participantes, além da $\mathrm{SPE}^{7}$ :

a) poder concedente, em geral o Estado;

b) acionistas (sponsors) - eles têm interesse direto no projeto, que se torna mais uma oportunidade de negócio;

c) compradores (off-takers);

d) financiadores (lenders) - bancos, agências bilaterais e multilaterais, fundos de pensão e fundos de investimento;

e) operadores (operators);

f) banco líder (arranger) - é o estruturador, um dos bancos envolvidos 
no financiamento, que possui a missão de estruturar o financiamento e é o responsável pelos termos do empréstimo e pela documentação;

g) fornecedores (suppliers);

h) construtores (constructors);

i) seguradoras (insurance companies);

i) conselheiro financeiro (financial advisor) - geralmente, um banco comercial de reconhecida reputação, cujo papel é instruir os acionistas quanto aos riscos envolvidos e quais seriam os instrumentos e as fontes de financiamento que poderiam mitigá-los;

k) engenheiro independente (independent engineer) - desempenha papel semelhante ao dos auditores independentes, ou seja, assegura aos demais participantes a viabilidade e as condições técnicas do projeto;

1) agente fiduciário (trustee) - responsável pela administração do fluxo de caixa, pela realização de pagamentos e pelo controle sob o recebimento de receitas do projeto;

m) assessoria jurídica (legal advisors) devido à complexa estrutura contratual do $P F$, é uma das figuras mais importantes na fase de análise e preparação do financiamento.

$\mathrm{Na}$ estrutura típica do PF, todos os participantes estão envolvidos em algum risco e possuem responsabilidades específicas. Essas responsabilidades e os riscos devem estar enumerados nos contratos de financiamento. Os contratos de risco substituem as garantias usuais ${ }^{8}$ pelas garantias de performance do projeto. Desse arcabouço surge um arranjo jurídico complexo, oneroso e demorado, pois são várias as soluções a serem propostas. Nesse ponto, a estabilidade e a confiabilidade do ambiente legal, bem como o cumprimento dos contratos, são essenciais para a implantação do projeto.
Os contratos devem conciliar os diversos interesses envolvidos em um projeto, uma vez que pode haver divergências iniciais quanto a algumas concepções. Por exemplo, o órgão financiador do governo pode ter uma visão completamente distinta dos objetivos de um $\mathrm{PF}$ do que um grupo de investidores, mas ambos têm interesse em sua realização. Daí surgem, basicamente, três tipos de negociação necessários para a efetivação do projeto. O primeiro é definir o papel dos agentes interessados no controle da SPE, quanto cada um aporta e quem terá o poder de decisão e veto. $\mathrm{O}$ segundo define, entre os controladores e demais financiadores, os critérios de governança da SPE de acordo com as normas de financiamento do credor. O terceiro envolve o governo e os controladores, ou os candidatos a controladores, no caso de concessões. Devem, nesse ponto, ser definidos os compromissos perante o poder público e a sociedade, as obrigações, os prazos, as regras, os benefícios e a possibilidade de parceria.

Estabelecidas as obrigações e responsabilidades, podem-se definir as formas de financiamento do projeto (BENOIT, 1995). A primeira delas é o financiamento com recursos próprios dos acionistas (equity), pelo qual usualmente se começa um $P F$ e os acionistas passam a ter direito sobre a participação acionária da SPE. Dessa forma, podem-se distinguir duas variações:

a) equity direto, em que os investidores têm participação na administração e na operação;

b) equity portfólio, em que os investidores só fornecem os recursos financeiros e a administração é competência dos demais acionistas.

A segunda principal forma de financiamento advém de recursos de terceiros (debt). Os recursos de terceiros não implicam 
participação direta na SPE. Segundo Borges e Faria (2002, p. 263), "o atributo principal da dívida é o retorno sobre o investimento, compatível com o retorno tradicionalmente auferido em operações de crédito, mas provisionando proteção contra perdas provenientes, principalmente, dos ativos do projeto". A dívida pode ser contraída via negociações com os investidores ou por captações no mercado de capitais. No PF é interessante a participação de construtores, fornecedores, compradores e outros participantes no financiamento da SPE, especialmente quando o projeto visa a atender determinado consumidor ou fornecedor. Além disso, as agências governamentais podem oferecer linhas de crédito a empreendimentos estratégicos para a economia nacional.

Há ainda uma terceira forma, a de recursos híbridos (quasi equity), em que os recursos de terceiros assumem peculiaridades de recursos próprios, como as debêntures conversíveis em ações. Seu principal diferencial decorre de esses recursos serem preferidos pelos demais credores em caso de quebra, ou seja, somente os sócios têm preferência sobre eles.

Com essas formas de financiamento, surgem diversas fontes de financiamento (funding) necessárias aos grandes empreendimentos de infra-estrutura. Os principais financiadores do $P F$, além dos fornecedores na fase de construção, são aqueles que dispõem de grande volume de recursos e esperam retornos em longo prazo, como os fundos de pensão, alguns fundos de investimentos, seguradoras, bancos de investimento e outras instituições financeiras. Além disso, os governos podem financiar projetos em agências e bancos estatais, como o BNDES ou empresas estatais interessadas no projeto. No plano internacional, encontram-se as agências multilaterais, como o Fundo Monetário Internacional (FMI), o Banco Mundial (Bird) e o Banco Interamericano de Desenvolvimento (BID).

Existe ainda a alternativa do leasing, geralmente utilizada para bens de capital. As captações no mercado de capitais - como Certificado de Depósito Bancário (CDB), commercial papers, debêntures, ações, opções e futuros - contribuem para o levantamento de recursos de curto prazo para o empreen-

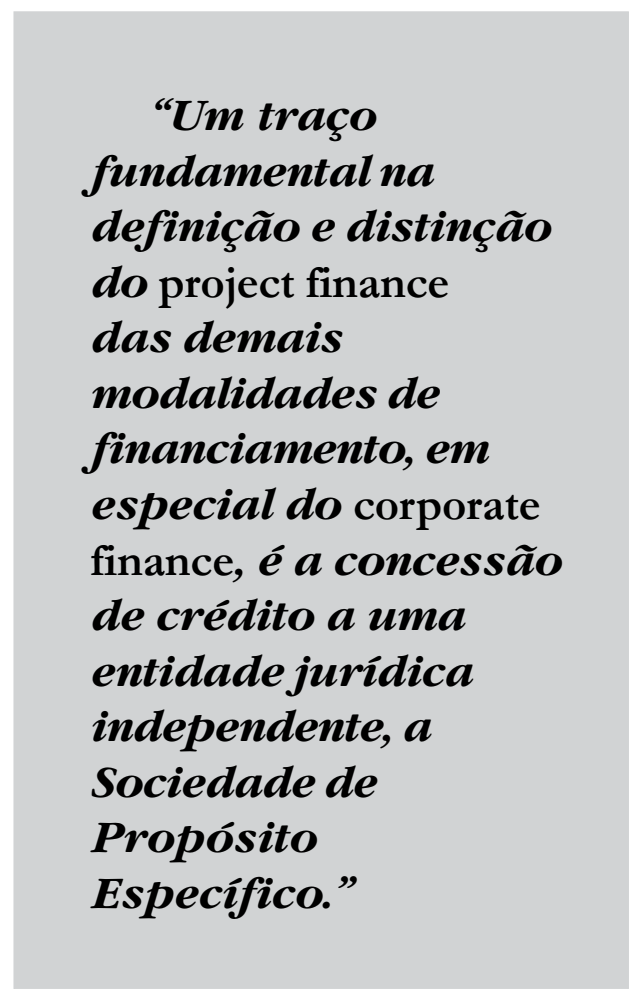

dimento. No caso brasileiro, devem-se ressaltar duas características negativas associadas a esses financiamentos. Em primeiro lugar, ainda não há desenvolvimento efetivo dos fundos de pensão e fundos de investimento de longo prazo, o que leva à segunda característica: um mercado de capitais ainda incipiente para a demanda de recursos para projetos de infraestrutura. Esse fato faz com que o $P F$, no 
Brasil, apresente riscos maiores e necessidade de garantias adicionais para a concessão de financiamentos de longo prazo.

\section{Riscos, garantias e estratégias mitigadoras}

O PF apresenta diferentes tipos de riscos para os diversos participantes envolvidos. $\mathrm{Na}$ teoria econômica, ocorre risco quando são conhecidos os vários resultados e as probabilidades de cada um deles, decorrentes de um conjunto de ações em uma situação. Quando as probabilidades são desconhecidas, há incerteza. Dessa forma, os riscos estão associados às possibilidades de inadimplência do devedor. Ao se analisar a classificação de riscos de diversos autores ${ }^{9}$, podem-se resumir riscos de duas origens distintas: os riscos do projeto e os riscos do país.

Entre os riscos do projeto, há os de construção, os de operação e os financeiros. Os riscos de construção envolvem a possibilidade de atraso, abandono da obra por parte da empresa encarregada, aumento de custos para a construção, escolha de tecnologia inadequada, risco ambiental, desistência dos participantes e avaliações e estimativas erradas. Os riscos de operação envolvem a falta de suprimento, o mercado consumidor, a ingerência operacional, o preço de produto inadequado, risco operacional técnico e de custo, danos ambientais, utilização de tecnologia inadequada, além do risco legal nos diversos contratos. Os riscos financeiros, por sua vez, dizem respeito às taxas de juros, ao risco cambial e do sindicato dos credores.

Os riscos do país, ou soberano, estão associados a características políticas, econômicas, sociais e geográficas específicas de determinado país. O risco político está ligado à capacidade de um governo mudar as normas institucional-legais para os investidores, como reajustes tarifários e alterações nos impostos. O risco macroeconômico envolve alterações bruscas na condução das políticas monetária, fiscal e cambial, de modo a alterar variáveis econômicas, como o crescimento, a inflação, a taxa de câmbio, as taxas de juros, o déficit público e a dívida pública. Existe ainda o risco por caso fortuito ou força maior (acts of $G o d)$, relacionado à eventualidade surgida da ocorrência de fato que possa implicar perda substancial ou total do capital, como catástrofes naturais advindas de características geográficas e catástrofes de cunho sociocultural. $\mathrm{O}$ risco soberano envolve, portanto, a credibilidade do governo e a estabilidade das instituições.

O risco soberano, no Brasil, tem passado por fortes oscilações. O Gráfico 1, a seguir, mostra a variação do prêmio de risco soberano do Brasil para títulos de 30 anos durante o período de agosto de 1998 a dezembro de 1999, quando ocorreu a crise cambial. Pode-se notar que, com o início da crise, em janeiro de 1999, o risco se elevou significativamente devido à perda de confiança e de credibilidade do Brasil no cenário externo. A perspectiva do risco soberano deve ser analisada de forma detalhada para projetos de $P F$, pois a sua alteração poderia comprometer sua implementação, mesmo considerando a maior estabilidade alcançada após a crise de 1999.

Há, contudo, várias medidas mitigadoras dos riscos envolvidos no PF, como seguros, contratos, instrumentos de mercado, oneração de ativos, participação de instituições internacionais, consócio de agentes financeiros, escrow account e outros. Cada instrumento mitigador atende a um risco específico. O risco financeiro pode ser diluído por um consórcio de agentes financeiros, que repassam seus riscos a 
terceiros, em um tipo de resseguro. Podese ainda dividir o projeto em módulos com prazos e condições distintas.

Os instrumentos de mercado, como as operações de hedge nos mercados derivativos (opções e futuros), os swaps e contratos de taxas de juros, também podem diminuir o risco de variáveis macroeconômicas sobre as finanças do projeto.

Os riscos políticos podem ser atenuados pela assunção de financiamentos em bancos locais, supondo que estes seriam estéreis a crises internacionais, pressuposto que dificilmente é verificado. A obtenção de recursos de agências multilaterais diminui a exposição ao risco político do país. Essas agências também oferecem seguros contra riscos políticos. Os seguros são bastante difundidos para o risco de força maior, mesmo que cubram até determinado limite. Relaciona-se ainda o seguro-garantia, que é um contrato acessório que visa a assegurar a plena satisfação do objeto contratual.

Os riscos legais envolvem a elaboração de medidas mitigadoras e a constituição de garantias, o acompanhamento de medidas legais e administrativas, a negociação de inadimplência e ações judiciais, de forma a reduzir o risco de todo projeto. Os contratos são amplamente utilizados para minimizar os riscos em transações financeiras, devendo ser compatíveis com a legislação vigente das partes envolvidas. Os vários tipos de contratos envolvem o pagamento periódico de quantidade de produtos ou serviços recebidos ou não, a garantia de venda, de compra, de preços e custos e de fornecimento de matéria-prima.

A estrutura de garantias, como expõem Monteiro Filha e Castro (2000, p. 110), é variável importante do ponto de vista dos financiadores, devendo ser negociada na

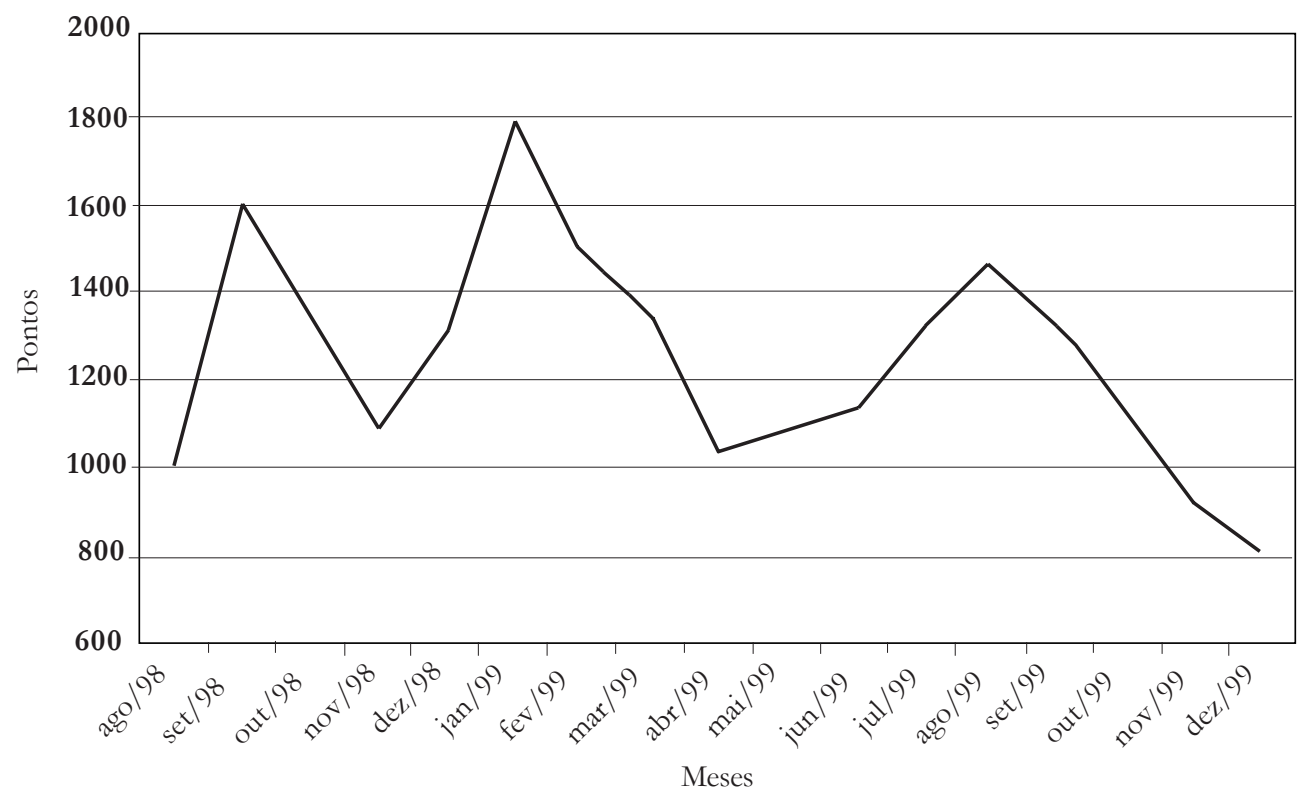

Fonte: J. P. Morgan

* Pontos básicos sobre o bônus do Tesouro dos EUA, de características semelhantes.

Gráfico 1: Brasil: prêmio de risco soberano - 30 anos* - ago./98 - dez./99 
concessão de empréstimos. Segundo os autores, existem três sistemas de garantias: full recourse, limited recourse e non recourse. $\mathrm{O}$ full recourse envolve um sistema tradicional de garantias e os atenuantes de risco não são usualmente utilizados. Os outros dois modelos são utilizados quando existem contratos de compra e venda de longo prazo. No non recourse, as garantias são ativos do próprio projeto e a qualidade do fluxo de caixa é da estrutura tradicional do PF. Já o limited recourse é um sistema intermediário com garantias tradicionais e recebimentos futuros. Os autores apresentam um estudo de Howcroft e Fadhley, em que mostram a participação das estruturas de garantia em projetos de PF realizados pelo setor bancário. Apesar de a estrutura tradicional non recourse ter participação de $21 \%$, a participação de várias outras estruturas e de combinações é bem intensa. Essas combinações são extremamente úteis nos casos de infra-estrutura, especialmente no Brasil, onde algumas peculiaridades mencionadas impedem a adoção de estrutura puramente non recourse, o que mostra a grande versatilidade do $P F$ nesses empreendimentos.

\section{Project finance em infra-estru- tura e o papel das estatais nas PPPs}

Os investimentos em infra-estrutura necessitam de aportes elevados de recursos, exigindo maior grau de alavancagem, o que tem contribuído para a utilização do $P F$. Ademais, o fluxo regular de recursos e a participação de número maior de participantes diminuem o risco e ampliam a possibilidade de utilização dessa forma de financiamento em todo o mundo. Entre as principais experiências mundiais, podem-se mencionar o Euro Tunnel (França/Inglaterra), o North-South Expressway (Malásia), o Bankok Second Stage Expressway (Tailândia), o Sydney Harbour Tunnel (Austrália) e o Sajião Power Plant (China) (Rodrigues JúnIOR, 1997, p. 46).

Os governos, para viabilizar as PPPs em infra-estrutura, devem saber a demanda da sociedade para definir os empreendimentos, de forma a alocar os recursos necessários. A PPP em infra-estrutura exige longos prazos de maturação e equalização dos interesses dos diversos atores. Um dos atores fundamentais para o sucesso de iniciativas desse vulto, no Brasil, são as empresas estatais de direito privado, dada

\section{Tabela 1 - Estruturas de project finance}

Participação dos tipos de estruturas no total de $P F$ realizado*

\begin{tabular}{l|c}
\hline Tipos de estruturas de $\boldsymbol{P F}$ & Participação no mercado (\%) \\
\hline Non recourse & 7 \\
Garantia referente a compromissos dos sponsors & 14 \\
Acordo em caso de déficit de caixa & 15 \\
Garantia de pre-completion** & 21 \\
Financiamento full recourse & 21 \\
Mistura de garantias (limited finance) & 22 \\
\hline Total & $\mathbf{1 0 0}$ \\
\hline
\end{tabular}

Fonte: Howcroft e Fadhley, citados em Monteiro Filha e Castro (2000, p.112).

* Número de bancos da amostra $=28$.

** Completion $=$ conclusão física do projeto. 
a sua importância para economia e a sua capacidade de investimento. O importante a se destacar é que esses investimentos são, muitas vezes, essenciais para o crescimento e desenvolvimento econômico do país em longo prazo. Além de novos empreendimentos (green field), também são necessárias as ampliações dos empreendimentos existentes (brown field) para o atendimento da crescente demanda por infra-estrutura.

Com relação ao desenvolvimento social, os investimentos em infra-estrutura são fundamentais na diminuição da pobreza, à medida que ampliam a oportunidade de acesso a bens públicos essenciais, com fortes externalidades ${ }^{10}$ positivas para toda a sociedade. Do mesmo modo, as estatais cumprem com seu papel social, associando seu funcionamento segundo a lógica privada com alguns objetivos públicos, de interesse comum a toda sociedade. O crescimento sustentável do país depende sobremaneira de sua capacidade de gerar os insumos de infra-estrutura necessários. A ampliação e a disseminação da tecnologia permitem diminuir o preço de bens de custo unitário elevado, ampliando seu consumo pela sociedade.

O PF pode atuar para solucionar o tradeoff dos serviços de utilidade pública. Essa contradição decorre do fato de esses serviços requererem grandes montantes de investimento em tecnologias caras, mas precisam operar com baixo custo para atender a toda a população. Ao se deslocarem as garantias para seu fluxo de caixa, pode-se diminuir o custo dos serviços, pois os financiamentos tradicionais teriam custo maior.

Dadas as características socioeconômicas brasileiras, esses investimentos são de difícil concretização sem a participação do Estado e de empresas estatais de direito privado, seja atuando como regulador dos serviços, seja atuando como financiador dos projetos. O equilibrio fiscal torna-se condição sine qua non para a efetivação desse papel do Estado como parceiro estratégico dos setor privado e das estatais. Outra possibilidade seria a parceria entre estatais e empresas privadas para a garantia de investimos nos setores de infra-estrutura. O governo pode assumir, portanto, a função de promotor ou de facilitador de investimentos em infra-estrutura. O project finance permite compatibilizar as duas posições, possibilitando ainda o aprimoramento do marco regulatório, devido à intensa troca de experiências com o setor privado e com as estatais.

Conforme Rodrigues Júnior (1997, p. 27), vários países, como a Coréia do Sul, as Filipinas, os EUA e o Japão, possuem tributos vinculados a investimentos em infra-estrutura. Esses recursos garantem continuidade da política de investimentos diante das descontinuidades orçamentárias decorrentes de decisões políticas. Contudo, a vinculação impede a securitização das receitas tributárias, o que prejudicaria o $\mathrm{PF}$. Outros países adotam esquemas de subsídios cruzados, pois alguns setores apresentam quebras de monopólio natural, garantindo, assim, a rentabilidade inicial do empreendimento $^{11}$. A relação entre investimentos e incentivos de infra-estrutura com a política fiscal é estreita e envolve, na maioria das vezes, algum sistema tributário específico. As obrigações tributárias são parcela importante do fluxo de caixa das empresas, mas, ao mesmo tempo, compõem uma peça fundamental do equilíbrio fiscal do governo. Contudo, a transferência da maioria dos investimentos ao setor privado, a conseqüente diminuição das despesas de capital e a elevação da arrecadação de tributos indiretos sobre os serviços de infra-estrutura podem compensar as perdas de arrecadação com 
benefícios fiscais. Nessa forma, o PF assume papel importante na política fiscal, mesmo que o governo não participe diretamente nos investimentos, pois viabiliza os investimentos sem contribuir para a elevação do déficit público.

O governo e as estatais, no PF, assumem ainda posição de fomento a novos empreendimentos, visando, sobretudo, a complementar a ação do mercado de capitais, ainda muito incipiente no Brasil. Destaca-se, assim, a função exercida pelo BNDES, principal órgão do governo envolvido nos projetos de PF. Segundo Borges e Faria (2002, p. 265), o BNDES tem peso expressivo em operações internas como provedor de recursos de longo prazo, atuando por agentes repassadores, em renda fixa e em renda variável. Os autores salientam que esse papel está gerando até mesmo uma distorção devida ao peso excessivo do BNDES nesse mercado de crédito. O BNDES atua como agente detentor de grande know-how em PF, especialmente nas relações jurídicas específicas brasileiras. $\mathrm{O}$ banco estabeleceu o limite mínimo de $20 \%$ de capital próprio, sendo que as operações de longo prazo tiveram em torno de $70 \%$ de repasses e $30 \%$ de participação do banco. Seu papel também inclui a análise de projetos detalhada, de modo a garantir sua lucratividade, a concessão de garantias essenciais ao PF e a articulação dos diversos participantes envolvidos. Ademais, a disseminação dos conceitos do $P F$ tem sido preocupação contínua de seu corpo técnico. O BNDES é o principal representante do Estado brasileiro para a viabilização das políticas públicas de infra-estrutura. Na condição de agente financeiro, o banco também pode realizar projetos rentáveis, que garantam novos fluxos de investimentos e movimentem mais recursos no mercado financeiro.
Para o setor privado e também para as estatais, os investimentos em infraestrutura possuem elevados potenciais de lucratividade (RODRIGUES JÚNIOR, 1997, p. 16). Além disso, os mercados de infraestrutura são consideravelmente mais estáveis que outros mercados e mais seguros que aplicações financeiras de alta volatilidade. Assim, o setor privado tem grandes incentivos em participar de parcerias com o setor público, de modo a viabilizar investimentos nesses setores. Entre os setores com maior potencial de negócios para o PF no Brasil, podem-se elencar: energia hidrelétrica e termelétrica, petróleo e gás, petroquímica, transportes, terminais portuários, telecomunicações, saneamento, mineração, parques industriais de commodities, lazer de grande porte e edificações públicas (Piccinini, 1996). Tais setores, como se pode perceber, são essenciais ao desenvolvimento econômico e social do País, de modo que sua garantia pela estratégia de parceria público-privada, envolvendo as estatais, viabilizada pelo project finance, é fundamental para o desenvolvimento sustentável da sociedade brasileira.

\section{Conclusão}

O papel do Estado tem sido reformulado ao longo das últimas décadas. A crise dos anos 70 reduziu sobremaneira a capacidade fiscal dos governos, de modo que os investimentos em infra-estrutura até então realizados foram reduzidos drasticamente. Uma das soluções encontradas para manter o fluxo de investimentos e garantir o crescimento econômico foi a transferência de ativos de infra-estrutura ao setor privado, bem como a concessão para a exploração de novos serviços de infraestrutura. No Brasil, as privatizações 
tiveram início na década de 1980, mas somente se efetivaram na segunda metade da década posterior, quando grandes empresas de serviços públicos foram privatizadas. As empresas estatais de direito privado remanescentes, cada vez mais seletivas, tornaram-se agentes fundamentais para o desenvolvimento do País, não mais pelo seu tamanho, mas por sua eficiência e excelência, como é o caso da Petrobras.

As privatizações propiciaram também maior interação entre o setor público e o setor privado, além de ampliar a lógica de gestão profissional nas estatais. Essa interação foi o primeiro passo para o estabelecimento de parcerias público-privadas. A necessidade de novos investimentos e a percepção de que esses investimentos não podem ser mantidos somente pelo Estado, somente pelo mercado ou somente pelas estatais tornam viáveis as parcerias. Ademais, o setor privado busca ambiente de equilíbrio macroeconômico e estabilidade institucional, condições essas também fundamentais para o ajuste fiscal do governo. A delegação de funções do Estado ao setor privado deu origem a outras formas de parceria, além da participação de setores de infra-estrutura privatizados, gerando novas instituições resultantes do processo de reforma. As estatais também se inserem nesse processo como parceiras do governo ou de outras empresas, buscando garantir, de um lado, o retorno sobre seu investimento e, de outro lado, o crescimento econômico do País.

Vários são os modelos de parceria, sendo que, em geral, eles envolvem a criação de uma SPE para a gestão do projeto. Essas sociedades concentram diversos participantes com interesses distintos, e uma das modalidades mais comuns para criação de um consórcio para explorar serviços de infra-estrutura é o project finance.
O PF tem como ponto fundamental a antecipação de recebíveis pela securitização de receitas e a diluição dos riscos entre os participantes, pois cada um assume uma responsabilidade. Torna-se possível, então, maior alavancagem financeira, devido à grande quantidade de participantes e à diluição de riscos, convertendo benefícios privados em benefícios públicos, pois os bens de infra-estrutura são de grande utilidade para toda a sociedade. Ao

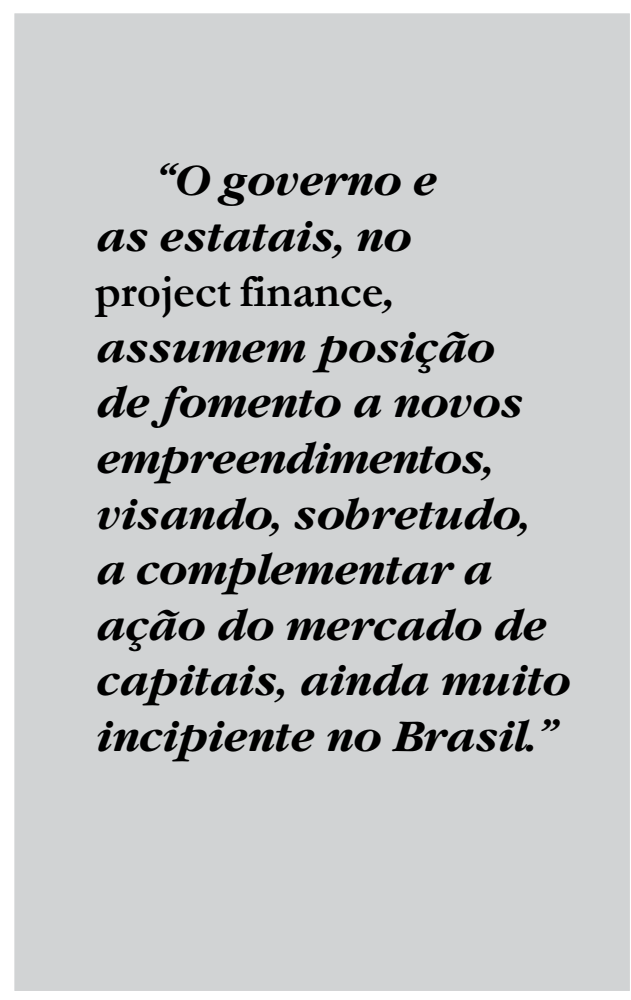

tratar contabilmente a SPE de forma diferente de seus controladores, o PF contribui para obtenção de melhores taxas de risco e evita a contaminação com os balanços dos controladores. Essa é uma oportunidade para que as empresas estatais estabeleçam parcerias com a administração direta ou com o setor privado, de modo a garantir os investimentos em infra-estrutura necessários ao País. 
Ao envolver vários participantes, como sócios, bancos, financeiras, seguradoras, fornecedores, compradores, estatais, governo e construtores, o PF contribui para a transparência na gestão do projeto e na divulgação das informações. Há o aprimoramento da governança corporativa, o que possibilita ingresso de recursos ainda maior. Com mais participantes, o risco torna-se ainda mais segregado, garantindo melhores condições para novos investimentos. A substituição de garantias usuais por garantias de performance permite maior flexibilidade a acionistas e credores, além de disponibilizar recursos para investimentos em curto prazo. De outra margem, os recebimentos são garantidos pelas receitas operacionais do projeto.

O PF é uma alternativa de financiamento e, como tal, pode ser menos interessante do que outra. A decisão de investimento em um projeto via project finance deve exigir minuciosa análise técnica de viabilidade.

Mesmo que não seja parte do escopo deste trabalho, é crucial mencionar os riscos jurídicos desse modelo no Brasil. Embora este artigo foque nas oportunidades para interação das empresas estatais, esse é um desafio iminente na implantação desse tipo de arranjo. Como apontam Borges (1998) e Borges e Faria (2002), a cultura jurídica brasileira, especialmente no cumprimento dos contratos, é bem distinta dos países anglo-saxões de direito consuetudinário, nos quais se originou o PF. Os autores enfatizam a necessidade de se adequarem os instrumentos jurídicos ao arcabouço brasileiro, sobretudo no que se refere às suas interfaces com o direito público. Os conflitos com outras legislações vigentes também podem configurar grandes riscos na implantação desse tipo de instrumento no Brasil.

Outro ponto importante é a adaptação dos fluxos financeiros efetivos com a previsão, de modo a garantir o equilíbrio financeiro do projeto e o recebimento dos investidores, valendo-se, para tanto, de instrumentos de garantia, como a contagarantia bloqueada.

A implantação do PF depende do ambiente macroeconômico, social, legal, político e regulatório do país, de modo a minimizar as incertezas e os riscos de cenários futuros. No Brasil, ainda é incipiente o mercado de capitais para o financiamento de longo prazo. Tal fato, em grande parte, deve-se à existência de poucos fundos de pensão, parceiros indispensáveis para parcerias em infra-estrutura. Esses fundos, com grande disponibilidade de recursos, necessitam de retornos em longo prazo, o que é ideal no PF. Assim, a atuação das estatais pode estimular esse mercado. Cabe também ao governo incentivar a disseminação dos fundos como instrumentos de formação da poupança nacional para a viabilização de investimentos. A ampliação do mercado de seguros também expande as possibilidades de alavancagem.

O governo tem ainda o papel fundamental de incentivar os investimentos e garantir o respeito aos contratos assinados com os concessionários de serviços públicos. Estes, por sua vez, devem cumprir suas obrigações contratuais. A confiança e a credibilidade nas relações dos participantes envolvidos são fundamentais para o sucesso do projeto. Daí a necessidade de ambiente regulatório estável e confiável.

Os investimentos em infra-estrutura são essenciais no crescimento e desenvolvimento de longo prazo do país. Esses investimentos demandam parceria entre o setor público, as empresas estatais e o setor privado para sua viabilização. Estratégias que viabilizem essas parcerias, como o $P F$, consolidam novo papel do Estado e das 
próprias empresas estatais, podendo, portanto, contribuir para o desenvolvimento sustentável da sociedade brasileira e ainda garantir o retorno financeiro aos acionistas e às próprias estatais. Logo, o papel destas torna-se cada vez mais importante no estímulo ao crescimento e desenvolvimento da sociedade brasileira.

(Artigo recebido em julho de 2006. Versão final em julho de 2006)

\section{Notas}

${ }^{1}$ A respeito dos motivos da participação do Estado na economia brasileira e em outros países, ver Giambiagi e Além (2000), Trebat (1980) e Baer, Newfarmer e Trebat (1976).

${ }^{2} \mathrm{Na}$ prática, o rolling back the state significou a privatização em massa e a desregulamentação das empresas estatais, na tentativa de reduzir de forma extrema os gastos públicos (ABruCio, 1997, p.15).

${ }^{3}$ Veja, por exemplo, o papel da Petrobras no atual cenário econômico brasileiro.

${ }^{4}$ Banco Nacional de Desenvolvimento Econômico e Social. Criado pela Lei no 1.628, de 1952, com a finalidade de financiar a formação de infra-estrutura essencial à industrialização do País, sendo a principal fonte nacional de financiamento de longo prazo. Em 1990, foi gestor do Fundo Nacional de Desestatização (FND) e apoiou técnica, administrativa e financeiramente o PND. Exerceu ainda papel fundamental nas privatizações após 1995 como financiador de longo prazo.

${ }^{5}$ A expressão "corporate finance", segundo Borges e Faria (2002), significa a concessão de crédito calcada em abordagem tradicional de análise e de instrumentos de garantia, ou seja, avaliação usual de crédito em função do histórico, do balanço patrimonial e, principalmente, da reputação do tomador do crédito. Adicionalmente, utilizam-se garantias tradicionais, como patrimônio, carta de fiança e demais ativos oferecidos pelos acionistas ou avalistas. Nesse caso, a preocupação dos credores limitase à capacidade financeira dos devedores em saldar as suas dívidas e, a princípio, não há nenhuma preocupação em relação à alocação dos recursos.

${ }^{6}$ Os ratings são classificações de risco indicando a probabilidade de inadimplência, atribuídos com base em informações fornecidas pela própria empresa, principalmente as suas demonstrações financeiras. Eles dependem da probabilidade de inadimplência da empresa e da proteção dada pelo contrato de empréstimo em caso de inadimplência.

${ }^{7}$ Optou-se por utilizar os termos em inglês entre parênteses por ser a denominação comum na literatura e na prática do project finance.

${ }^{8}$ Ativos, cartas de fiança, aval dos acionistas, hipoteca, carta de crédito, entre outros.

${ }^{9}$ Ver Borges e Faria (2002), Finnerty (1999), Tinsley (2000) e Nevitt e Fabozzi (1995).

${ }^{10}$ Ocorrem quando o bem-estar de um consumidor ou as possibilidades de produção de uma firma são diretamente afetados pelas ações de um outro agente da economia. De outra forma, as externalidades podem ser definidas como os efeitos sobre uma terceira parte, derivadas de uma transação econômica sobre a qual a terceira parte não tem controle. Externalidades positivas são efeitos que aumentam o bemestar dessa terceira parte (por exemplo, reduzindo os custos de produção), enquanto externalidades negativas são efeitos que reduzem o bem-estar (por exemplo, aumentando os custos de produção).

${ }^{11}$ Os monopólios naturais apresentam economias de escala, que ocorrem quando o custo médio da firma se reduz (ou o produto médio aumenta), quando a produção cresce, a preços dados 
de insumos. Analogamente, ocorre quando uma firma possui custo total de produção menor do que a soma dos custos de duas ou mais firmas, produzindo o mesmo bem ou serviço. A quebra de um monopólio natural pode acabar com esses ganhos e gerar prejuízos para a empresa em um momento inicial

\section{Referências bibliográficas}

ABrucio, Fernando Luiz. O impacto do modelo gerencial na administração pública: um breve estudo sobre a experiência internacional recente. Cadernos ENAP, Brasília, $\mathrm{n}^{\circ}$ 10, 1997.

Azeredo, A. R. Financiamento de longo prazo no Brasil: project finance como alternativa para a infra-estrutura. Rio de Janeiro: UFRJ/Coppead, 1999.

Baer, Werner; Newfarmer, Richard; Trebat, Thomas. Considerações sobre o capitalismo estatal no Brasil: algumas questões e problemas novos. Pesquisa e Planejamento Econômico, v. 6, n 3, dez. 1976.

Benoit, P. Project finance at the World Bank: an overview of policies and instruments. Washington, D.C., 1995. (World Bank Technical Paper, 312.)

Borges, L. X. F. Project finance e infra-estrutura: descrição e críticas. Revista do BNDES, Rio de Janeiro, v. 5, nº 9, p. 105-122, jun. 1998.

Borges, L. F. X.; Faria, V. C. S. Project finance: considerações sobre a aplicação em infra-estrutura no Brasil. Revista do BNDES, Rio de Janeiro, v. 9, nº 18, p.241-280, dez. 2002.

CARvalho, Wagner. A reforma administrativa da Nova Zelândia nos anos 80-90: controle, estratégia, eficiência gerencial e accountability. Revista do Serviço Público, v. 48, n. 3, set./dez. 1997.

Finnerty, J. D. Project finance. Rio de Janeiro: Qualitymark, 1999.

Giambiagi, Fábio; AlÉm, Ana Cláudia. Finanças públicas: teoria e prática no Brasil. 2. ed. Rio de Janeiro: Campus, 2000.

Macedo, M. E.; Alves, A. M. Reforma administrativa: o caso do Reino Unido. Revista do Serviço Público, v. 48, nº 3, set./dez. 1997.

MarTins, Luciano. Estado capitalista e burocracia no Brasil pós-64. Rio de Janeiro: Paz e Terra, 1985. (Coleção Estudos Brasileiros, 82.)

Monteiro Filha, D. C.; CASTRO, M. P. S. Project finance para a indústria: estruturação de financiamento. Revista do BNDES, Rio de Janeiro, v. 7, no 14, p.107-124, dez. 2000.

Moreira, Terezinha,; Carneiro, Maria C. F. A parceria público-privada na infra-estrutura econômica. Revista do BNDES, Rio de Janeiro, v. 1, nº 2, p.27-46, dez. 1994.

NevitT, Peter. K.; FabOzZi, Frank. Project financing. 6 ed. London: Euromoney Publications, 1995. 
Pêgo Filho, B.; Lima, E. C. P.; Pereira, F. Privatização, ajuste patrimonial e contas públicas no Brasil. Brasília: IPEA, 1999. (Texto para Discussão, 668.)

Pereira, L. C. B. Reforma do Estado para a cidadania: a reforma gerencial brasileira na perspectiva internacional. São Paulo: Ed. 34, 1998.

- A reforma do Estado nos anos 90: lógica e mecanismos de controle.

Pereira, L. C. B.; Spink, P. (Org.). Reforma do Estado e administração pública gerencial. Rio de Janeiro: Fundação Getúlio Vargas, 1998.

Piccinini, M. A infra-estrutura nas diferentes esferas do setor privado e a participação da iniciativa privada. Rio de Janeiro: BNDES, 1996.

Pinheiro, José M.; Giambiagi, Fábio. Lucratividade, dividendos e investimentos das empresas estatais: uma contribuição para o debate sobre a privatização no Brasil. Revista Brasileira de Economia, v. 51, n 1, jan./mar. 1997.

Reunião do Círculo de Montevidéu, 2, 1997, BARCELONA. Disponível em: <http://www.bresserpereira.ecn.br>.

Rodrigues JúnIOR, Waldery. A participação privada no investimento em infra-estrutura e o papel do project finance. Brasília: IPEA, 1997. (Texto para Discussão, 495.)

TINSLEY, Richard. Advanced project finance: structuring risk. London: Euromoney Publications, 2000 .

TreBAt, Thomas. Uma avaliação do desempenho econômico de grandes empresas estatais no Brasil: 1965/75. Pesquisa e Planejamento Econômico, v. 10, n 3, dez. 1980. 


\title{
Resumo - Resumen - Abstract
}

\author{
As estatais e as PPPs: o project finance como estratégia de garantia de investimentos \\ em infra-estrutura \\ Wagner Frederico Gomes de Araújo
}

Este trabalho discute o papel das estatais nas PPPs, de modo a garantir investimentos em infraestrutura pelo financiamento via project finance. Partindo de um contexto de privatizações desse setor, que, no Brasil, efetivou-se na década de 1990, buscou-se mostrar como surgiu espaço para o estabelecimento de PPPs, advindas de novas instituições resultantes do processo de reforma do Estado. O project finance é colocado como uma forma de garantir o financiamento desses investimentos. Sua estrutura financeira, baseada na criação de uma pessoa jurídica para a gestão do empreendimento, busca dirimir os riscos pela elevação do número de participantes e pela securitização de receitas futuras, tornando-as líquidas em curto prazo. A discussão sobre o papel do project finance revela que essa é uma estratégia viável para a garantia de investimentos por parte das estatais, em parceria com o governo e com outras empresas, que levem ao desenvolvimento socioeconômico sustentável do País.

Palavras-chave: project finance; parceria público-privada; empresas estatais

Las empresas estatales y las asociaciones público-privadas: el project finance como una estrategia de garantía de inversiones en el sector de infraestructura

Wagner Frederico Gomes de Araújo

Este artículo discute el rol de las empresas estatales en las APPs como medio de garantizar las inversiones en el sector de infraestructura vía project finance. Se empieza con la discusión sobre las privatizaciones en los años 90 en Brasil, que permitieron el surgimiento de nuevas instituciones como las APPs. El project finance se presenta como forma de financiar estas inversiones. Su estructura financiera, basada en la creación de una sociedad de propósito específico, busca reducir los riesgos por medio de la elevación del no de participantes. Se muestra, así, como una estrategia viable para garantizar las inversiones de las empresas estatales en el sector de infraestructura, en asociación con el gobierno y otras empresas.

Palabras clave: project finance; asociación público-privada; empresas estatales

State-owned companies and public-private partnerships: a strategy to ensure infrastructure investments through project finance

Wagner Frederico Gomes de Araújo

This study discusses the role played by state-owned companies in PPPs in order to ensure infrastructure investments through project finance. The article starts with the debate over the privatization process that took place, in Brazil, in the 90's, within a larger movement of State reform, which paved the way to the establishment of new institutions such as the PPPs. Project finance is presented as a mean of funding PPPs in infrastructure projects. Its financial structure involves the creation of a special purpose company, which seeks to properly allocate risks by increasing the number of stakeholders and securitizing future revenues. Project finance reveals itself as a feasible strategy to ensure investments by state-owned companies in partnership with the government and other companies.

Keywords: project finance; public-private partnership; state-owned companies

Wagner Frederico Gomes de Araújo

Administrador, mestre em Ciência Política pela UFMG e Especialista em Políticas Públicas e Gestão Governamental do Governo do Estado de Minas Gerais. Atua também como professor universitário na Escola de Governo da Fundação João Pinheiro, na Faculdade Promove e nas Faculdades Arnaldo Jansen. Contato: <waraujo04@yahoo.com>. 